\title{
Response of term babies to a warm environment
}

\author{
N. RUTTER AND D. HULL \\ University Hospital and Medical School, Nottingham
}

SUMMARY The response of healthy term babies to warm environments was assessed by placing them naked in incubators and increasing the air temperature in steps until either sweating occurred or the rectal temperature reached $37.9^{\circ} \mathrm{C}$. The rate of evaporation of water from the skin was measured by a method based on the estimation of vapour pressure gradient. When a $50 \%$ increase in the rate occurred at a given site, sweating was judged to have begun. 39 studies were made on 30 babies, aged from 4 hours to 11 days. As babies approached the point of sweating, spontaneous activity usually ceased, the skin reddened, and a sunbathing posture was adopted. Sweating was found on 35 occasions. It was most pronounced and often was found initially on the forehead but it was also detected on the trunk and limbs. No thermal sweating was noted on the palms or soles. Sweating generally began when the incubator air temperature exceeded $34^{\circ} \mathrm{C}$ and the rectal temperature exceeded $37 \cdot 1{ }^{\circ} \mathrm{C}$, but there was wide individual variation. Older and more mature babies tended to sweat at lower air temperatures.

Sweating is man's most important defence against overheating. It is highly developed in the heatacclimatised adult who can lose over a litre of water an hour by this route, an evaporative heat loss of $700 \mathrm{~W}$. Before sweating occurs, skin blood flow is increased which raises skin temperature and increases heat loss by radiation and convection. By these adjustments adults are able to maintain deep body temperatures within a narrow range in high environmental temperatures. Very few investigations have been made on the response of the newborn baby to high ambient temperatures. By virtue of his size the newborn in the company of adults is more at risk of cold exposure. However, the clinical emphasis on the importance of keeping babies warm has led to the introduction of powerful heating devices, such as incubators and radiant warmers, into routine service and with this has come the risk of overheating. Just as it is important to know the ambient temperatures at which babies of different ages, sizes, and gestations switch on thermogenesis thus increasing their need for oxygen and substrate, so it is important to know the ambient temperatures at which they are likely to begin to sweat and thus increase their need for water.

Department of Child Health, Nottingham

N. RUTTER, lecturer in child health

D. HULL, professor of child health
A simple method for measuring evaporative water loss from the skin is available (Nilsson, 1977). We used this in combination with measurements of skin temperature to study the range of responses of the healthy term baby to high environmental temperatures.

\section{Method}

Rates of evaporation of water from the skin were measured with the Evaporimeter EP1 (Servomed), a method based on estimation of the water vapour pressure gradient close to the skin's surface. The technical details have been reported by Nilsson (1977).

Each baby after a feed was placed naked on his back inside an incubator (Vickers 79). The air temperature of the incubator was set near the lower point of the thermoneutral range according to the values reported by Hey (1971). The probe of the Evaporimeter was placed lightly on the baby's skin until a stable reading of evaporation rate was obtained. Measurements were made at 11 defined skin sites on each baby: forehead, cheek, chest, abdomen, anterior upper arm and forearm, palm, anterior thigh and lower leg, dorsum of the foot and sole. These sites were chosen so that the infant lying on his back was not disturbed. At the same 
time, the following temperatures were measured by thermocouple: air temperature in the centre of the incubator, skin temperature of the upper abdomen and dorsum of the hand by lightly taping the thermocouple to the skin, and rectal temperature, with a probe inserted about $8 \mathrm{~cm}$ into the baby's rectum.

30 minutes were allowed for the infant to adjust to any change in environmental conditions. After the initial readings were made, the incubator air temperature was increased in steps of $0 \cdot 5-1 \cdot 5^{\circ} \mathrm{C}$. 30 minutes later, evaporation rates and temperatures were recorded before the incubator air temperature was again increased, and this sequence was continued until the baby began to sweat or until his rectal temperature reached $37.9^{\circ} \mathrm{C}$. This is the average body temperature of babies before birth (Mann, 1968). As sweating is influenced by exercise as well as by temperature, measurements were not made on active or crying babies. In this study sweating was defined as an increase in evaporation rate of at least $50 \%$ above the initial rate of water loss from that skin site. In most cases the increase was considerably greater, in some instances 10 to 18 times higher than the initial values. The upper critical temperature of the thermoneutral range is usually defined as that environmental temperature at which sweating first occurs. As the incubator air temperature was increased in steps, the upper critical temperature for each baby was somewhere between the air temperature at which sweating did not occur and the air temperature at which it did. Because this point was not accurately defined, we have expressed all our results in terms of the incubator air temperature at which sweating was first detected. This temperature is not the operative environmental temperature because no allowances were made for radiant heat exchange between the baby and the inner surface of the single-walled incubator. The average room temperature was $27 \cdot 2^{\circ} \mathrm{C}$ (range $24 \cdot 9-29 \cdot 9^{\circ} \mathrm{C}$ ). Thus the operative environmental temperature was likely to be about $1^{\circ} \mathrm{C}$ lower than the actual incubator air temperature (Hey and Mount, 1966). The relative humidity inside the incubator was not controlled but it was measured. It varied between 26 and $58 \%$.

39 studies were made on 32 healthy term babies. Gestational age was calculated in completed weeks of pregnancy from the first day of the mother's last menstrual period. It ranged from 37 to 42 weeks (mean 39.7). Birthweight ranged from 2.77 to $4.70 \mathrm{~kg}$ (mean 3.48 ). The age of the baby varied from 4 hours to 11 days. Each study was made with the full informed consent of the mother, usually in her presence, and the investigation was approved by the North Nottinghamshire Health District Ethical Committee.

\section{Results}

The results of a typical series of observations are illustrated in Fig. 1. With each increment in incubator air temperature, the peripheral temperature on the dorsum of the hand rose sharply. Abdominal skin and rectal temperatures also rose, but at a slower rate. After $30 \mathrm{~min}$ at an incubator air temperature of $36 \cdot 6^{\circ} \mathrm{C}$, when the peripheral and abdominal skin temperatures were the same and the difference between skin and rectal temperature was only $0.5^{\circ} \mathrm{C}$, the baby began to sweat.

The incubator temperatures were never raised so that the infant's rectal temperature exceeded $37 \cdot 9^{\circ} \mathrm{C}$. With this limitation, sweating was detected in 35 out of the 39 studies. On 11 occasions sweating was only noted on the forehead. On 14 occasions it occurred on the forehead first and only appeared elsewhere when the air temperature was further raised. It then progressed to the chest, arms, abdomen, and legs, usually in that sequence. On the remaining 10 occasions, sweating was noted at several sites simultaneously, always including the forehead. The mean rates of evaporation of water at the different sites, initially and after sweating occurred, are shown in the Table. Sweating was most pronounced on the forehead.

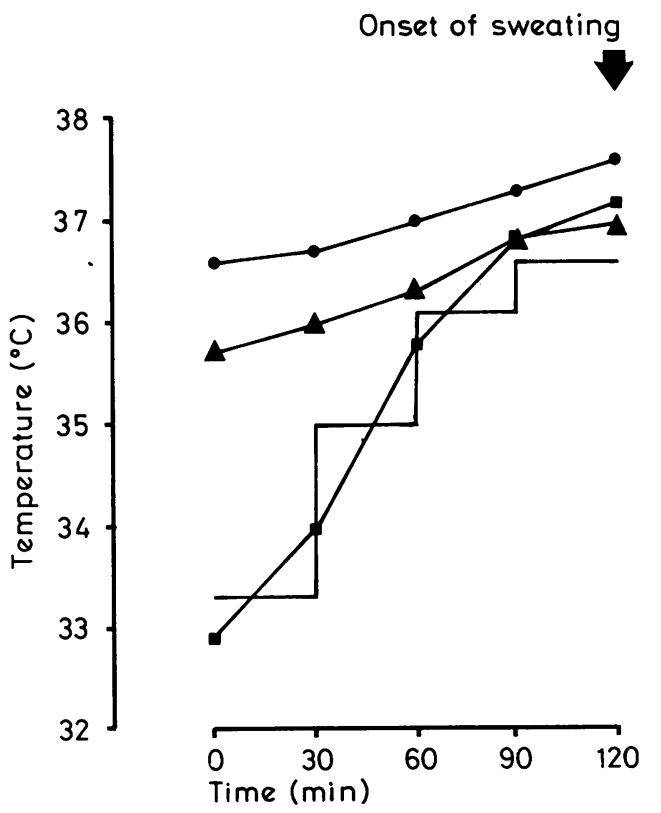

Fig. 1 The effect of step-wise increases in the incubator temperature (-) on body temperatures ( - rectal, $\Delta$ abdominal skin, $\square$ hand) of a naked, term infant, birthweight $2.95 \mathrm{~kg}$, age 21 hours. The arrow head indicates when sweating began. 
Table Mean rates of evaporation from different skin sites in 39 babies. Initial rates were obtained after the baby had been naked in an incubator for 30 min at $a$ temperature near the lower end of the thermoneutral range. Sweating was judged to have occurred when, after increasing the ambient temperature, the evaporation rate increased by at least $50 \%$ above the initial value

\begin{tabular}{llll}
\hline Skin site & $\begin{array}{l}\text { Mean initial } \\
\text { evaporation rate } \\
\left(\mathrm{g} / \mathrm{m}^{2} \text { per hour }\right)\end{array}$ & $\begin{array}{l}\text { Mean maximum } \\
\text { evaporation rate } \\
\text { when sweating } \\
\left(\mathrm{g} / \mathrm{m}^{2} \text { per hour }\right)\end{array}$ & $\begin{array}{l}\text { No. of times } \\
\text { sweating detected } \\
\text { (no. of studies }= \\
39)\end{array}$ \\
\hline Forehead & 6.2 & 52.6 & 35 \\
Cheek & 8.2 & 16.2 & 13 \\
Chest & 4.8 & 16.7 & 21 \\
Abdomen & 4.9 & 11.3 & 15 \\
Upper arm & 5.6 & 12.5 & 14 \\
Forearm & 5.2 & 15.3 & 18 \\
Palm & 14.6 & -5 & 0 \\
Thigh & 5.4 & 12.3 & 11 \\
Lower leg & 4.9 & 11.8 & 12 \\
Foot-dorsum & 4.6 & 13.2 & 7 \\
Foot-sole & 9.6 & - & 0 \\
\hline
\end{tabular}

There were wide variations in the incubator air temperatures, the rectal temperatures, and the abdominal skin temperatures at which sweating was first detected (Fig. 2). There was a significant trend for infants of longer gestations to sweat at lower ambient temperatures but there was no obvious difference in the skin and rectal temperatures at which sweating first occurred in the more mature babies (Fig. 3). Infants who were at least 6 days old, sweated at significantly lower ambient temperatures than infants in the first 4 days of life, but again no change in the skin and rectal temperatures when sweating occurred was noted as the postnatal age increased (Fig. 4). Four infants were studied serially during the first week of life. In all 4 the air temperature at which sweating was first observed fell by $1 \cdot 3-2 \cdot 6^{\circ} \mathrm{C}$. The relative humidity of the incubator air, in the range of $26-58 \%$, did not appear to influence the ambient temperature at which sweating first occurred.
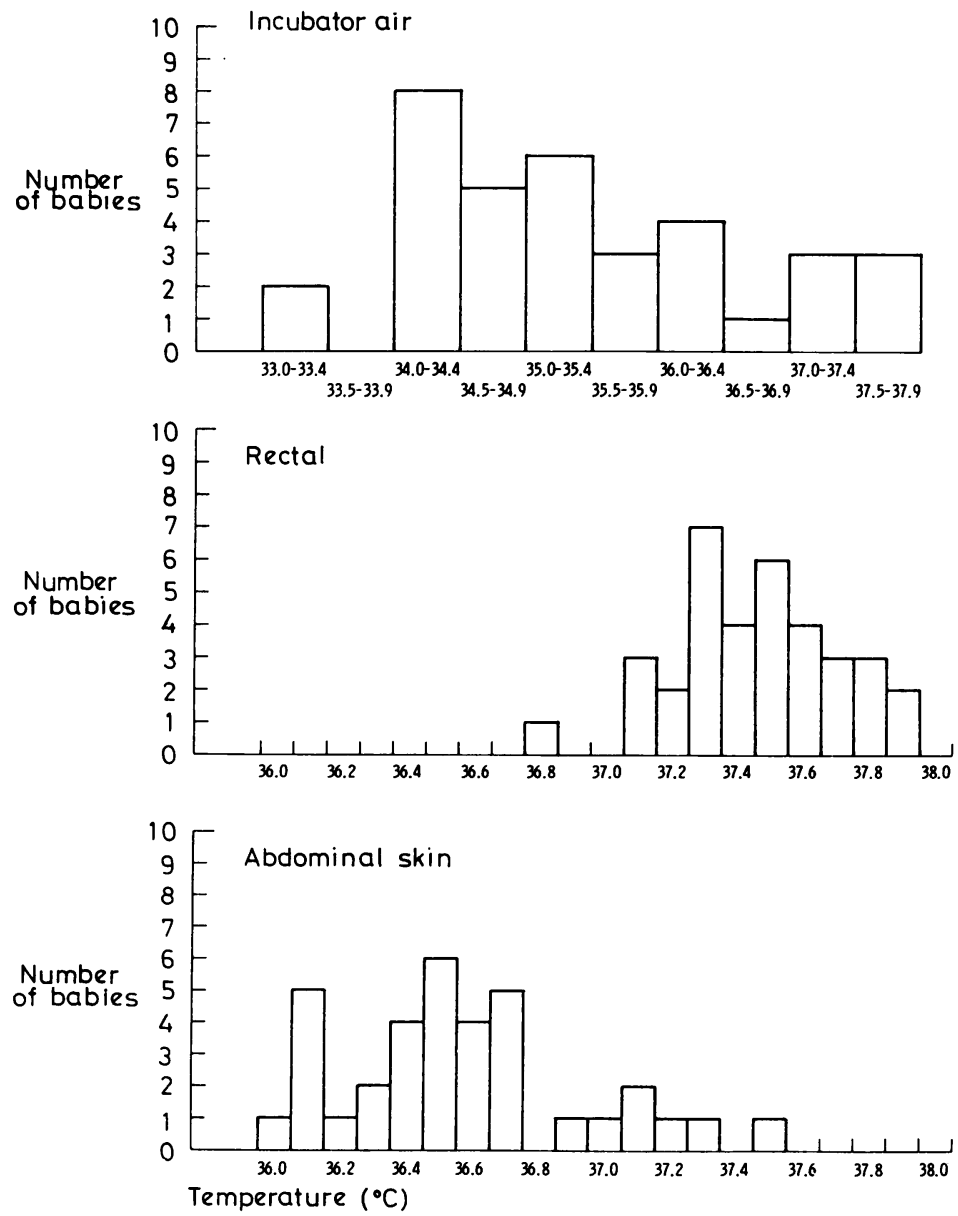

Fig. 2 Temperatures of the incubator air, rectum, and abdominal skin at which sweating was first detected in 35 infants. 

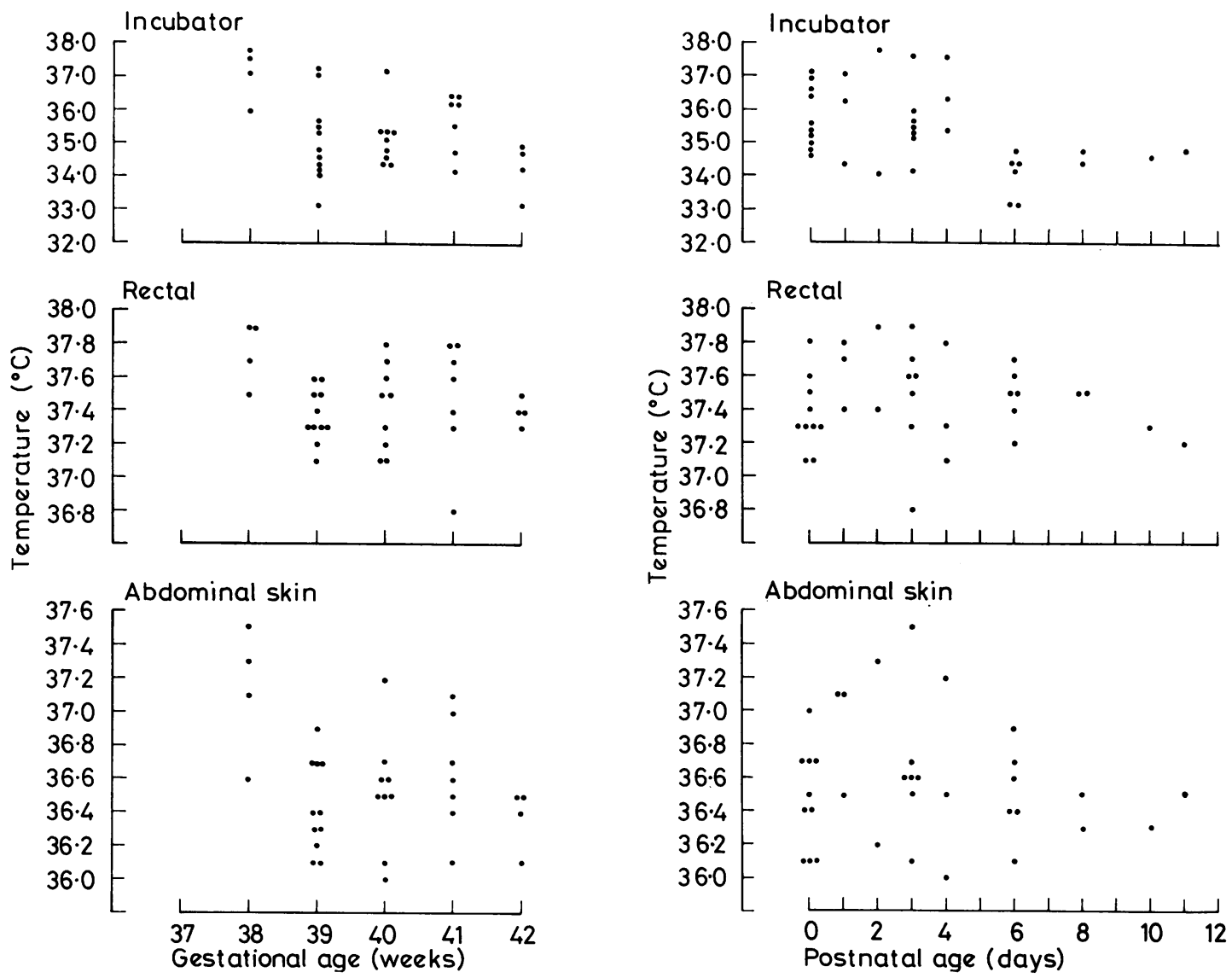

Fig. 3 Relationship between gestational age and the incubator air, rectal, and abdominal skin temperatures at which sweating first occurred. The more mature infants began to sweat at lower incubator air temperatures $(P=0.05)$.

In the infants who did sweat, sweating occurred when the peripheral and abdominal skin temperatures were similar and the rectal and skin temperatures differed by about $0.5^{\circ} \mathrm{C}$. In the 4 infants who did not sweat, these conditions were reached and all the measured temperatures then rose with each upward step in ambient temperature without detectable sweating (Fig. 5).

In a few instances, sweat was visible on the forehead when rates of sweating were very high but usually it was not seen. Certainly the onset of sweating could not be detected visually. However, the infants did make consistent responses to the increasing ambient temperature. As the air temperature rose the skin colour reddened, spontaneous movements diminished, and when sweating began

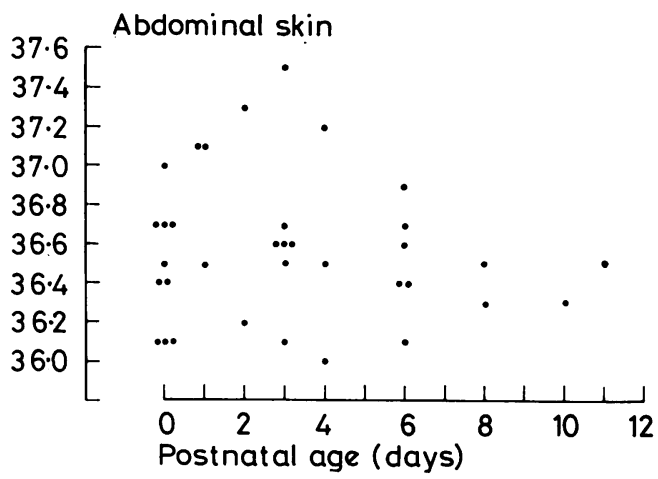

Fig. 4 Relationship between postnatal age and the incubator air, rectal, and abdominal skin temperatures at which sweating first occurred. Babies aged 6 days or more, sweat at significantly lower air temperatures than those aged 4 days or less $(P=0.01)$.

the infants assumed the posture of a sunbathing adult, lying supine with arms and legs outstretched (Fig. 6). No panting was observed.

\section{Discussion}

Sweat response. We have demonstrated that term babies are able to sweat and that sweating readily occurs on the first day of life. This was not found by Uchino (cited by Kuno, 1956) who measured water loss from the chest only, but it was reported by Hey and Katz (1969) who measured total evaporative water loss in a metabolic chamber. We cannot explain why 4 babies did not sweat in spite of high rectal temperatures, although 2 were shown on a later occasion to be able to do so. We found that 


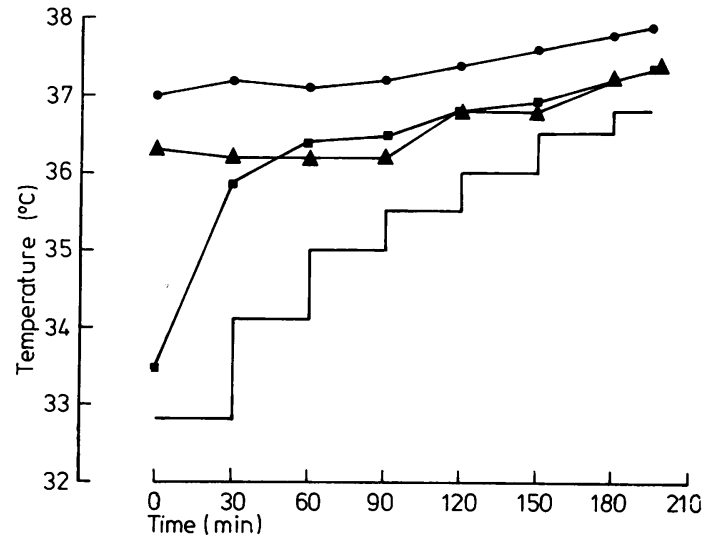

Fig. 5 The effect of step-wise increases in the incubator temperature (-) on body temperatures ( 1 rectal, $\Delta$ abdominal skin, $\square$ hand) of a baby in whom no sweating was detected. The baby was born at 37 weeks' gestation, weighing $3.41 \mathrm{~kg}$, and was 6 days old when studied.

the forehead was the earliest site at which sweating occurred, that it was usually most intense there, and that it was sometimes the only site where a sweat response was detected. We chose the centre of the forehead because it was a convenient site for measurement but sweating of similar intensity was found simultaneously on the temples, behind the ears, and over the occiput but sparing the top of the scalp. Sweating on the forehead of the newborn infant was observed by Foster et al. (1969); they pointed out that the sweat glands at this site are the first to develop in fetal life. When progression of sweating occurred, the order from head to chest, arms, abdomen, and legs was similar to that described in adults (Rothman, 1954). Furthermore the $\overrightarrow{\vec{F}}$ relative intensity of sweating at the different sites is similar to adults (Kuno, 1934), but absolute values are generally lower. It must be pointed out however, $\bar{\omega}$. that we did not attempt to press the infants to their $\vec{\varnothing}$ maximum possible rates of sweating. Hey and Katz 2 (1969) found that evaporative water loss per unit $\infty$ area is lower in the sweating baby than the sweating $\overrightarrow{0}$ adult. The high initial rates of water loss from the $\vec{A}$ palms and soles which did not change as ambient $\bar{\omega}$ temperature increased were noted in adults by Kuno (1934). Perpetual sweating is thought to occur at these sites and cannot be abolished by cooling; in described as emotional or mental sweating, it can be $\omega$ induced in an adult by mental arithmetic or anxiety. $\vec{v}$

Both gestational age and postnatal age influenced $\infty$ the environmental temperature at which sweating occurred but there was much individual variation. Many factors are likely to be involved, including maturation of control systems, variations in thermal insulation, and differences in resting metabolic rates. The charts of Hey (1971) suggest that term babies nursed naked in incubators do not greatly increase their evaporative water loss until the operative environmental temperature reaches about $34^{\circ} \mathrm{C}$ on the first day or $33^{\circ} \mathrm{C}$ at about 10 days of age. Our results are generally consistent with these observations, as only a few babies sweated at temperatures below these and most babies did so at temperatures $0 \cdot 5-1 \cdot 0^{\circ} \mathrm{C}$ higher. The fall in incubator air temperature at which sweating first occurred as postnatal age increased was independent of gestational age. It mirrors the rise in resting metabolic rate which

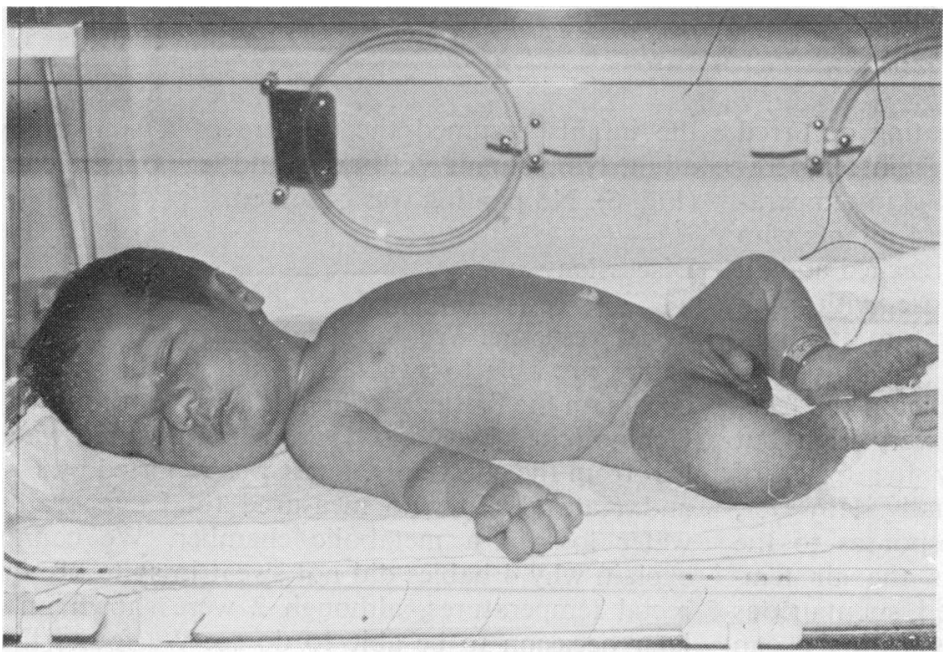

Fig. 6 Typical sunbathing posture of a sweating baby. 
occurs during the first week of life (Hill and Rahimtulla, 1965). Unlike Hey and Katz (1969), we did not find that the rectal temperature at which sweating first occurred was lower in the more mature or older babies. In fact rectal temperatures varied widely and were not a good guide to the onset of sweating. Rectal temperature was usually rising at the time sweating started but sometimes it was static or falling. It is evident that body temperature as reflected by the rectal temperature is not the trigger for sweating and that its measurement is not a useful guide to thermal comfort.

Other responses. As the environmental temperature increased, the babies attempted to maintain deep body temperature by increasing heat loss by radiation and convection from the skin. This was shown by a rise in skin temperature and abolition of the temperature gradient between peripheral and central skin sites. Rectal temperature often rose slightly while this was occurring. All temperatures then rose steadily together until sweating occurred. To augment heat loss the baby exposed as much of his surface area as possible by lying on his back with limbs outstretched, keeping heat production at a minimum by inactivity. Heat loss by these mechanisms of changing skin blood flow and posture is not great when the ambient temperature is close to the skin temperature. In fact when ambient temperature reaches and exceeds skin temperature these mechanisms are a disadvantage to the baby and increase his heat gain. Under these circumstances only an increase in evaporative water loss can keep deep body temperature within normal limits and prevent hyperpyrexia.

How can we tell when a term newborn baby is too warm? Usually the ambient air temperature if the infant is naked will be above $34^{\circ} \mathrm{C}$, his rectal temperature will be $37 \cdot 2^{\circ} \mathrm{C}$ or greater, and his abdominal skin temperature will be above $36 \cdot 3^{\circ} \mathrm{C}$. There is wide individual variation. However, most babies sweat when their peripheral and central skin temperatures are the same or similar. Although sweat may not be visible, healthy babies do by their skin colour, activity, and posture indicate that they are too hot.

We thank the midwives and nursing staff of ward 3A, Nottingham City Hospital Maternity Unit, for their help. We are grateful to the Special Trustees for Nottingham University Hospitals who supplied financial support for the purchase of the Evaporimeter.

\section{References}

Foster, K. G., Hey, E. N., and Katz, G. (1969). The response of the sweat glands of the new-born baby to thermal stimuli and to intradermal acetylcholine. Journal of Physiology, 203, 13-29.

Hey, E. N. (1971). The care of babies in incubators. In Recent Advances in Paediatrics, fourth edition, pp. 171-216. Edited by D. Gairdner and D. Hull. Churchill: London.

Hey, E. N., and Mount, L. E. (1966). Temperature control in incubators. Lancet, 2, 202-203.

Hey, E. N., and Katz, G. (1969). Evaporative water loss in the new-born baby. Journal of Physiology, 200, 605-619.

Hill, J. R., and Rahimtulla, K. A. (1965). Heat balance and the metabolic rate of new-born babies in relation to environmental temperature; and the effect of age and of weight on basal metabolic rate. Journal of Physiology, 180, 239-265.

Kuno, Y. (1934). The Physiology of Human Perspiration. Churchill: London.

Kuno, Y. (1956). Human Perspiration. Thomas: Springfield.

Mann, T. P. (1968). Observations on temperatures of mothers and babies in the perinatal period. Journal of Obstetrics and Gynaecology of the British Commonwealth, 75, 316-321.

Nilsson, G. E. (1977). Measurement of water exchange through the skin. Medical and Biological Engineering and Computing, 15, 209-227.

Rothman, S. (1954). Physiology and Biochemistry of the Skin, chapter six, pp. 158-161. University of Chicago Press: Chicago.

Correspondence to Professor D. Hull, University Hospital and Medical School, Department of Child Health, Clifton Boulevard, Nottingham NG7 2UH.

Received 4 July 1978 